\title{
Comparison Between Pediatricians and Physicians in Other Medical Specialties in Promoting Smoking Cessation in the Clinic
}

\author{
Mary Vetter, BS, ${ }^{1}$ Katharine Thomas, MS, MD, ${ }^{1,2}$ Alaa Mohammed, MPH, CME, ${ }^{3}$ Fernando Urrego, MD ${ }^{1,4}$ \\ ${ }^{1}$ The University of Queensland School of Medicine, Ochsner Clinical School, New Orleans, LA ${ }^{2}$ Department of Internal Medicine, \\ Ochsner Clinic Foundation, New Orleans, LA ${ }^{3}$ Office of Biostatistical Support, Ochsner Clinic Foundation, New Orleans, LA \\ ${ }^{4}$ Department of Pediatric Pulmonology, Ochsner Clinic Foundation, New Orleans, LA
}

Background: Louisiana has one of the highest rates of smoking in the country, putting its children at high risk of secondhand and third-hand smoke exposure and subsequent morbidity. Pediatricians have an important role to play by including smoking cessation promotion (SCP) in their discussions with patient caregivers. The purpose of this study was to examine SCP trends at Ochsner Health System and to determine if pediatricians are less likely to express confidence in and performance of SCP activities than physicians in other specialties.

Methods: We distributed a survey to pediatricians and to physicians in the departments of obstetrics and gynecology, internal medicine, and psychiatry in the Ochsner Health System. The survey assessed physician confidence in and performance of several SCP behaviors. We analyzed pediatrician confidence in and performance of 3 behaviors (screening, counseling, and referring) and compared pediatrician responses to the responses of the physicians in the other specialties.

Results: Twenty-eight pediatrician and 33 other physician responses were included in the analysis. No significant correlation $(P=0.2785)$ was found between pediatrician confidence and performance in screening for smoking behavior. A significant correlation was found in counseling $(P=0.0159)$ and referring $(P=0.0214)$. In the comparison of pediatrician responses to other physician responses, the physicians in the other specialties had higher medians and/or quartiles for both confidence and performance of all 3 behaviors, and the differences were significant.

Conclusion: The physicians in other specialties showed consistently higher rates of confidence and performance of SCP behaviors than the pediatricians. Intervention is necessary to encourage pediatricians at Ochsner Health System to promote smoking cessation in their practices.

Keywords: Pediatrics, smoking cessation, tobacco smoke pollution

Address correspondence to Fernando Urrego, MD, Department of Pediatric Pulmonology, Ochsner Clinic Foundation, 1514 Jefferson Hwy., New Orleans, LA 70121. Tel: (504) 833-2337. Email: furrego@ochsner.org

\section{INTRODUCTION}

For more than half a century, we have known the detrimental effects of exposure to the smoke created by burning tobacco products. We know that smoking is not only a risk to the smoker but also to others through unintentional inhalation (ie, secondhand smoke). ${ }^{1,2}$ Since the 1964 Surgeon General's Report first described the health consequences of smoking, more than 20.8 million deaths in the United States have been attributed to nicotine exposure, and 2.5 million of these deaths were attributed to secondhand smoke exposure. ${ }^{1,2}$ Secondhand smoke exposure in children is associated with sudden infant death syndrome, prematurity, and low birth weight, leading to 100,000 deaths in the pediatric population per year. ${ }^{1,2}$ Additionally, children in particular exposed to secondhand smoke are known to have an increased risk of middle ear disease, as well as respiratory symptoms and impaired lung function. ${ }^{1,2}$ Further, environmental tobacco smoke, which includes secondhand and third-hand smoke exposure, causes increased incidences of wheeze, asthma, cough, phlegm, bronchitis, bronchiolitis, and pneumonia in children. The severity of these illnesses is directly related to amount of exposure. ${ }^{3}$ Children with asthma who are exposed to environmental tobacco smoke have more frequent symptoms, nighttime awakenings, and need for medication and emergency room visits. ${ }^{4}$ Environmental tobacco smoke is also associated with behavioral problems, neurocognitive deficits, and future smoking during adolescence. ${ }^{3}$ 
Vetter, $M$

Third-hand smoke exposure generally comes in the form of residual pollutants that can be maintained in high concentrations in the air and on surfaces (including clothing and skin) after exposure to smoke. These pollutants can be reemitted or can combine with other compounds to form secondary pollutants. ${ }^{5}$ Pollutants can cause release of free radicals that can increase asthma and allergy symptoms, and correlations have been seen between even low levels of pollutant exposure and cognitive deficits in children. ${ }^{5}$ The nature of children's increased susceptibility to thirdhand smoke exposure can be attributed to a physiologic vulnerability to pollutants because of factors such as increased respiration compared to body size and immaturity of the immune system, as well as to behaviors such as crawling and ingestion of nonfood items. ${ }^{6}$ Symptoms of third-hand smoke exposure can occur in the home even when smokers only smoke outside. ${ }^{6}$

The primary care environment is an excellent setting for physicians to screen for secondhand and third-hand smoke exposure. General pediatricians have the opportunity to promote smoking cessation through screening caregivers for smoking behaviors, counseling caregivers on the health benefits of smoking cessation, and referring caregivers to smoking cessation programs. However, many pediatricians are not promoting smoking cessation during clinic visits. A study conducted by Winickoff et al demonstrated that only $38 \%$ of caregivers reported being advised of the risks of environmental tobacco smoke, and $40 \%$ reported being counseled to quit during their child's clinic visit. ${ }^{7}$

The need to decrease secondhand smoke exposure in the pediatric population is paramount. In 2016, the Centers for Disease Control and Prevention reported that $15.5 \%$ of US adults were currently smoking. ${ }^{8}$ In an analysis of smoking rates in adults per state, the state of Louisiana fell in the $21.8 \%-25.1 \%$ bracket, among the highest in the country. ${ }^{9}$ Additionally, a 2015 study demonstrated that $31 \%$ of caregivers of Ochsner pediatric patients smoke, which is twice the national rate in US adults. ${ }^{10}$ Together, these data show that the children in Louisiana are particularly vulnerable to the effects of secondhand and third-hand smoke exposure simply because of the number of smoking adults.

However, evidence shows that obstetrics and gynecology (Ob/Gyn), internal medicine, and psychiatry physicians are more likely to express confidence in or performance of smoking cessation promotion (SCP) activities compared to pediatricians. ${ }^{11-18}$ This situation is suboptimal given the clear evidence showing the harmful effects of environmental tobacco smoke exposure in children. A systematic review of SCP interventions in pediatrics showed that some interventions have been somewhat effective in increasing SCP, including the Clinical and Community Effort Against Secondhand Smoke Exposure (CEASE) and the National Cancer Institute (NCl) 5As (ask, advise, agree, assist, arrange). ${ }^{19}$ A 2016 study by Hall et al surveyed Ochsner Health System pediatricians about training in SCP and found that few pediatricians reported formal SCP training. ${ }^{20}$ To more fully understand SCP trends at Ochsner and to determine if pediatricians are less likely to express confidence in and performance of SCP activities than physicians in other specialties as shown in the literature, the objective of this study was to compare Ochsner Health System pediatric physicians' rate of SCP to physicians in Ob/Gyn, internal medicine, and psychiatry.

\section{METHODS}

After receiving exemption from the institutional review board, a survey (Figure) was designed for distribution to physicians in different departments at Ochsner Health System. The survey consisted of 2 parts: (1) the first question asked the physician's confidence level in practicing 12 behaviors associated with SCP, and (2) the second question asked how often the physician had actually performed each of the 12 behaviors in the past 6 months. The questions were adjusted for different specialties depending on whether physicians were being asked about their behaviors toward patients, pregnant patients (for Ob/Gyn physicians), or patient caregivers (for pediatricians). The responses were on 5-point Likert scales that were converted to a numerical 1-5 scale for data analysis. The online survey was distributed via email to the departments of general pediatrics, Ob/Gyn, psychiatry, and internal medicine. Three of the 12 behaviors were selected for analysis as these 3 behaviors were deemed the most crucial: screening for smoking behavior, counseling about cessation options, and referring to smoking cessation programs.

\section{Participants}

The number of responses varied between specialties. A total of 36 pediatricians were asked to participate and 28 responded for a response rate of $78 \%$. Sixty $\mathrm{Ob} / \mathrm{Gyn}$ physicians were asked and 11 responded for a response rate of $18 \%$. Sixty-five psychiatrists were asked and 10 responded for a response rate of $15 \%$. Forty-seven internal medicine physicians were asked and 12 responded for a response rate of $26 \%$. All participants entirely completed the surveys with the exception of $2 \mathrm{Ob} / \mathrm{Gyn}$ physicians who did not answer one of the questions.

\section{Statistical Methods}

SAS v.9.4 for Windows was used to conduct all analyses. Tests were performed at a significance level of $\alpha=0.05$, and values were considered significant if $P<\alpha$. Descriptive statistics were run for frequencies, mean, median, and standard deviation based on normality tests. Spearman test was used to measure the correlation between confidence and behavior for pediatricians and other physicians. Wilcoxon test was used to investigate the differences in response to all 6 questions between comparison groups.

\section{RESULTS}

The responses from the Ob/Gyn, internal medicine, and psychiatry specialties were grouped together for analysis $(n=33)$ to better match the pediatrician sample size $(n=28)$ and because of the focus of this study on pediatricians. When we looked for a correlation between physician responses to questions about their confidence and behaviors and their actual performance of these behaviors in the past 6 months, we found no significant correlation $(P=0.2785)$ between pediatrician confidence and performance in screening for smoking (Table 1); however, we found a significant correlation in counseling $(P=0.0159)$ and referring $(P=0.0214)$. As also shown in Table 1 , analysis of the responses from the other 3 physician groups showed significant correlations for all 3 behaviors: screening $(P=0.0006)$, counseling $(P=0.0001)$, and referring $(P<0.0001)$. 


\begin{tabular}{|c|c|c|c|c|c|}
\hline \multicolumn{6}{|c|}{ 1. Right now, to what extent are you confident to do each of the following? } \\
\hline & Definitely No & Not Really & Indifferent & Probably Yes & Definitely Yes \\
\hline \multicolumn{6}{|l|}{$\begin{array}{l}\text { Screen [caregivers, patients, pregnant } \\
\text { patients] for smoking behavior }\end{array}$} \\
\hline \multicolumn{6}{|l|}{$\begin{array}{l}\text { Counsel smoking [caregivers, patients, } \\
\text { pregnant patients] about cessation }\end{array}$} \\
\hline \multicolumn{6}{|l|}{$\begin{array}{l}\text { Refer [caregivers, patients, pregnant } \\
\text { patients] to smoking cessation programs }\end{array}$} \\
\hline \multicolumn{6}{|l|}{$\begin{array}{l}\text { Discuss [a child's health risk, the health } \\
\text { risk to others, a child's health risk in utero] } \\
\text { from secondhand smoke }\end{array}$} \\
\hline \multicolumn{6}{|l|}{$\begin{array}{l}\text { Advise smoking [caregivers, patients] to } \\
\text { quit }\end{array}$} \\
\hline \multicolumn{6}{|l|}{ Counsel on the health risks of smoking } \\
\hline \multicolumn{6}{|l|}{$\begin{array}{l}\text { Record smoking as a health problem in } \\
\text { the medical record }\end{array}$} \\
\hline \multicolumn{6}{|l|}{$\begin{array}{l}\text { Motivate [caregiver, patient] to quit } \\
\text { smoking }\end{array}$} \\
\hline \multicolumn{6}{|l|}{$\begin{array}{l}\text { Provide educational materials on self-help } \\
\text { smoking cessation }\end{array}$} \\
\hline \multicolumn{6}{|l|}{$\begin{array}{l}\text { Ask [caregivers, patients] if they are willing } \\
\text { to set a quit date }\end{array}$} \\
\hline \multicolumn{6}{|l|}{$\begin{array}{l}\text { Recommend use of nicotine replacement } \\
\text { therapy to quit }\end{array}$} \\
\hline $\begin{array}{l}\text { Schedule a follow-up to discuss quitting } \\
\text { (eg, office visit or telephone call) }\end{array}$ & & & & & \\
\hline
\end{tabular}

\section{In the past 6 months, how often do you include the behavior described as part of your routine medical} care of a patient?

\begin{tabular}{|c|c|c|c|c|c|}
\hline & Never & Rarely & Usually & Very Often & Always \\
\hline \multicolumn{6}{|l|}{$\begin{array}{l}\text { Screen [caregivers, patients, pregnant } \\
\text { patients] for smoking behavior }\end{array}$} \\
\hline \multicolumn{6}{|l|}{$\begin{array}{l}\text { Counsel smoking [caregivers, patients, } \\
\text { pregnant patients] about cessation }\end{array}$} \\
\hline \multicolumn{6}{|l|}{$\begin{array}{l}\text { Refer [caregivers, patients, pregnant pa- } \\
\text { tients] to smoking cessation programs }\end{array}$} \\
\hline \multicolumn{6}{|l|}{$\begin{array}{l}\text { Discuss [a child's health risk, the health } \\
\text { risk to others, a child's health risk in utero] } \\
\text { from secondhand smoke }\end{array}$} \\
\hline \multicolumn{6}{|l|}{$\begin{array}{l}\text { Advise smoking [caregivers, patients] to } \\
\text { quit }\end{array}$} \\
\hline \multicolumn{6}{|l|}{ Counsel on the health risks of smoking } \\
\hline \multicolumn{6}{|l|}{$\begin{array}{l}\text { Record smoking as a health problem in } \\
\text { the medical record }\end{array}$} \\
\hline \multicolumn{6}{|l|}{$\begin{array}{l}\text { Motivate [caregiver, patient] to quit smok- } \\
\text { ing }\end{array}$} \\
\hline \multicolumn{6}{|l|}{$\begin{array}{l}\text { Provide educational materials on self-help } \\
\text { smoking cessation }\end{array}$} \\
\hline \multicolumn{6}{|l|}{$\begin{array}{l}\text { Ask [caregivers, patients] if they are willing } \\
\text { to set a quit date }\end{array}$} \\
\hline \multicolumn{6}{|l|}{$\begin{array}{l}\text { Recommend use of nicotine replacement } \\
\text { therapy to quit }\end{array}$} \\
\hline $\begin{array}{l}\text { Schedule a follow-up to discuss quitting } \\
\text { (eg, office visit or telephone call) }\end{array}$ & & & & & \\
\hline
\end{tabular}

Figure. Survey used to assess confidence in and performance of smoking cessation promotion behaviors. 
Table 1. Correlation Between Confidence and Performance in Smoking Cessation Promotion Behaviors

\begin{tabular}{|c|c|c|c|c|}
\hline \multirow{2}{*}{$\begin{array}{l}\text { Smoking Cessation } \\
\text { Promotion Behavior }\end{array}$} & \multicolumn{2}{|c|}{$\begin{array}{l}\text { General Pediatrics } \\
\qquad(n=28)\end{array}$} & \multicolumn{2}{|c|}{$\begin{array}{l}\text { Other Physicians (Obstetrics/Gynecology, } \\
\text { Internal Medicine, Psychiatry) } \\
\qquad(n=33)\end{array}$} \\
\hline & $\mathbf{r}$ & $P$ Value & $\mathbf{r}$ & $P$ Value \\
\hline Screening & 0.20817 & 0.2785 & 0.58067 & 0.0006 \\
\hline Counseling & 0.45141 & 0.0159 & 0.61969 & 0.0001 \\
\hline Referring & 0.43294 & 0.0214 & 0.72188 & $<0.0001$ \\
\hline
\end{tabular}

A comparison of the responses for individual questions between the 2 groups showed that the median responses from the other physicians were higher for every question with the exception of one (Table 2). In all cases, the quartiles were higher in the other physicians group, and we found significant differences in the confidence and performance for all 3 behaviors when comparing the medians of these 2 groups.

\section{DISCUSSION}

The results from this study indicate that compared with Ochsner physicians of other specialties, Ochsner pediatricians are significantly less likely to screen for smoking behavior, provide smoking cessation counseling, and refer smokers to smoking cessation programs. Our findings support previous studies showing that elsewhere in the United States, physicians in specialties such as Ob/Gyn, internal medicine, and psychiatry report higher rates of SCP behaviors than pediatricians. ${ }^{11-18}$

The American College of Obstetricians and Gynecologists implementation of the $\mathrm{NCl} 5 \mathrm{As}$ in response to evidence of the health risks in children exposed to smoke in utero resulted in high rates of SCP by Ob/Gyn physicians. ${ }^{11-13} \mathrm{~A}$ statewide survey of $\mathrm{Ob} / \mathrm{Gyn}$ physicians in Ohio assessing their use of the 5 As showed that $98 \%$ asked pregnant patients about smoking behaviors, with $66 \%$ advising and $42 \%$ assessing. ${ }^{13}$ The 5 As strategy (sometimes reduced to $4 \mathrm{As}$ or $3 \mathrm{As}$ ) is used by physicians in other specialties as well. A statewide survey of physicians of various specialties in Rhode Island showed that internal medicine physicians performed the ask, advise, and assist behaviors more than $80 \%$ of the time. ${ }^{14}$ Internal medicine had the highest compliance rate of the specialties studied. Psychiatrists play an important role in SCP as well, given that people with psychiatric problems are twice as likely to smoke and smoke more than the general population. ${ }^{15}$ Psychiatrists reported screening for smoking status $76 \%$ of the time but only counseling $12 \%$ of the time in an analysis of the 1991-1996 data from the National Ambulatory Medical Care Survey. ${ }^{16}$ In a more recent (2007) study of psychiatrists in Ohio, 90\% expressed confidence in advising patients of smoking risk and 34\% expressed confidence in referring these clients. ${ }^{17} \mathrm{~A}$ survey of mental health clinicians not limited to physicians showed similarly high levels of confidence across a number of mental health professions. ${ }^{18}$

In a previous study, our research group demonstrated that pediatricians provided counseling and referred caregivers to smoking cessation programs significantly less than they screened for nicotine exposure. ${ }^{10}$ Our current study confirms that pediatricians are on par with other specialties in their likelihood to screen; however, they fall short in other smoking cessation behaviors. One potential reason for this deficit may be pediatricians' lack of confidence in their ability to counsel parents, thus leading to a decrease in their rate of SCP. Previous studies have shown that pediatricians reported low self-efficacy regarding counseling smoking caregivers

Table 2. Comparison Between Physician Groups of Responses to Questions About Smoking Cessation Promotion Behaviors

\begin{tabular}{|c|c|c|c|c|}
\hline $\begin{array}{l}\text { Smoking Cessation } \\
\text { Promotion Behavior }\end{array}$ & $\begin{array}{c}\text { General Pediatrics, } \\
\text { Median (Q1,Q3) } \\
(\mathbf{n}=\mathbf{2 8})\end{array}$ & $\begin{array}{c}\text { Other Physicians } \\
\text { (Obstetrics/Gynecology, } \\
\text { Internal Medicine, Psychiatry), } \\
\text { Median }(\mathbf{Q} 1, \mathrm{Q} 3) \\
(\mathrm{n}=\mathbf{3 3})\end{array}$ & $\mathbf{Z}$ & $P$ Value \\
\hline \multicolumn{5}{|l|}{ Confidence } \\
\hline Screening & $5(4,5)$ & $5(5,5)$ & -2.0373 & 0.0416 \\
\hline Counseling & $4(3,4)$ & $5(4,5)$ & -3.22261 & 0.0013 \\
\hline Referring & $3(2,4)$ & $5(4,5)$ & -2.7740 & 0.0055 \\
\hline \multicolumn{5}{|l|}{ Performance } \\
\hline Screening & $4(4,5)$ & $5(5,5)$ & -3.2558 & 0.0011 \\
\hline Counseling & $4(2,4)$ & $5(4,5)$ & -3.8949 & $<0.0001$ \\
\hline Referring & $2(2,4)$ & $4(2,5)$ & -2.3834 & 0.0172 \\
\hline
\end{tabular}

Q, quartile. 
and described a feeling of insufficient skills required for SCP and a low rate of specific training in SCP. ${ }^{21,22}$ Further, pediatricians often perceive parents as not needing advice or lacking interest in quitting, ${ }^{23,24}$ although parents reported that screening for smoking status was very important and those who intended to quit felt they would accept advice from their child's pediatrician. ${ }^{22}$ Some pediatricians reported feeling a general lack of confidence in the effectiveness of their interventions even if they were confident in their own training. ${ }^{25}$ Physicians who receive formal training report higher self-efficacy when asked about SCP. ${ }^{26}$

As pediatricians' confidence levels in SCP are often discussed in the literature, we aimed to assess this measure in our study. We found no correlation between pediatrician confidence and performance of screening for smoking behavior, which tells us that as pediatrician confidence increased, their performance of SCP did not necessarily increase. A low self-reported confidence could be attributable to factors such as inadequate training or discomfort with discussing the topic with caregivers. A number of reasons could explain this lack of correlation, one of which is that lack of confidence is not the primary problem with screening. If physicians are confident in screening, they still may or may not perform this behavior, indicating that other factors affect their SCP. These factors may include time management or perceptions about caregivers. In contrast, we saw a significant correlation between confidence and the behaviors of counseling and referring smoking patients or caregivers. In other words, pediatricians who are more confident also reported higher performance. These results could possibly show a greater effect of training on these behaviors in that pediatricians who were trained in SCP would theoretically be more confident and thus more likely to perform these behaviors. This correlation between confidence and performance was also found to be significant in the other physician group.

In our analysis of confidence and performance of each behavior individually, we found significant differences between pediatricians and other physicians in all 6 questions. The differences in medians and quartiles show that pediatricians reported lower levels of confidence and performance of SCP and that Ochsner pediatricians are behind the other specialties in SCP, contributing to a nationwide problem in the field of pediatrics.

\section{Limitations}

This study has limitations that may have impacted the results. The first limitation is the small sample size largely as a result of the low response rate from nonpediatric physicians. The expected reporting bias present in this type of survey is another limitation. We can speculate that physicians who would respond to a survey of this nature are more likely to be the type of physician who performs thorough screening. Additionally, physicians are potentially more likely to overestimate when reporting these behaviors.

\section{Future Directions}

If other specialties can maintain higher rates of SCP, then general pediatricians must be encouraged to screen, counsel, and refer caregivers they encounter in their practice. Further insight into the reasons for these discrepancies among specialties regarding SCP could be elicited in further studies, perhaps through administration of a more detailed survey asking pediatricians to explain their lack of confidence in and performance of SCP. Demographic information on surveyed physicians such as years of experience and type of training institution could be helpful in identifying other contributing factors. Once possible factors are determined through further study, interventional programs developed with this information can be instituted to help pediatricians become more efficient and effective in SCP.

\section{CONCLUSION}

This study shows that pediatricians who express more confidence in their ability to counsel and refer smoking caregivers tend to report regular performance of these behaviors in practice. Pediatricians at Ochsner also reported significantly different and effectively lower levels of SCP confidence and performance of screening, counseling, and referring caregivers in comparison with their counterparts in Ob/Gyn, internal medicine, and psychiatry. Further study to evaluate the reasons for these deficits to form valuable training interventions for pediatricians is crucial to improve SCP. An institution such as Ochsner could play a valuable role in decreasing the risks associated with secondhand and third-hand smoke exposure in the pediatric population of Louisiana.

\section{ACKNOWLEDGMENTS}

The authors have no financial or proprietary interest in the subject matter of this article.

\section{REFERENCES}

1. US Department of Health and Human Services. The health consequences of smoking -50 years of progress: a report of the Surgeon General. Atlanta, GA: US Department of Health and Human Services, Centers for Disease Control and Prevention, National Center for Chronic Disease Prevention and Health Promotion, Office on Smoking and Health. 2014;17. https://www.surgeongeneral.gov/library/reports/50-years-of -progress/full-report.pdf. Accessed September 11, 2018.

2. US Department of Health and Human Services. The health consequences of involuntary exposure to tobacco smoke: a report of the Surgeon General. Atlanta, GA: US Department of Health and Human Services, Centers for Disease Control and Prevention, Coordinating Center for Health Promotion, National Center for Chronic Disease Prevention and Health Promotion, Office on Smoking and Health. 2006;709. https:/ /www.surgeongeneral.gov/library/reports/secondhandsmoke /fullreport.pdf. Accessed September 11, 2018.

3. DiFranza JR, Aligne CA, Weitzman M. Prenatal and postnatal environmental tobacco smoke exposure and children's health. Pediatrics. 2004 Apr;113(4 Suppl):1007-1015.

4. Gilliland FD, Li YF, Peters JM. Effects of maternal smoking during pregnancy and environmental tobacco smoke on asthma and wheezing in children. Am J Respir Crit Care Med. 2001 Feb;163(2):429-436.

5. Merritt TA, Mazela J, Adamczak A, Merritt T. The impact of second-hand tobacco smoke exposure on pregnancy outcomes, infant health, and the threat of third-hand smoke exposure to our environment and to our children. Przegl Lek. 2012;69(10):717-720.

6. Ferrante G, Simoni M, Cibella F, et al. Third-hand smoke exposure and health hazards in children. Monaldi Arch Chest Dis. 2013 Mar;79(1):38-43. 
7. Winickoff JP, McMillen RC, Carroll BC, et al. Addressing parental smoking in pediatrics and family practice: a national survey of parents. Pediatrics. 2003 Nov;112(5):1146-1151.

8. Jamal A, Phillips E, Gentzke AS, et al. Current Cigarette Smoking Among Adults - United States, 2016. MMWR Morb Mortal Wkly Rep. 2018 Jan;67(2):53-59. doi: 10.15585/mmwr.mm6702a1.

9. US Department of Health and Human Services. Behavioral risk factor data: tobacco use (2011 to present). Centers for Disease Control and Prevention, National Center for Chronic Disease Prevention and Health Promotion, Office on Smoking and Health. 2018. https://healthdata.gov/dataset/behavioral-risk -factor-data-tobacco-use-2011-present. Accessed September 11, 2018.

10. Hall K, Egger AL, Dezara C, Kisely S, Urrego FA. The Smoking Cessation Trust Program of Louisiana: the pediatrician's role in identifying and referring eligible caregivers. Ochsner J. 2015 Fall;15(3):237-240.

11. ACOG Committee on Health Care for Underdeserved Women; ACOG Committee on Obstetric Practice. ACOG committee opinion. Number 316, October 2005. Smoking cessation during pregnancy. Obstet Gynecol. 2005 Oct;106(4):883-888.

12. Chapin J, Root W; American College of Obstetricians and Gynecologists. Improving obstetrician-gynecologist implementation of smoking cessation guidelines for pregnant women: an interim report of the American College of Obstetricians and Gynecologists. Nicotine Tob Res. 2004 Apr;6 Suppl 2:S253-S257.

13. Jordan TR, Dake JA, Price JH. Best practices for smoking cessation in pregnancy: do obstetrician/gynecologists use them in practice? J Womens Health (Larchmt). 2006 May;15 (4):400-441.

14. Goldstein MG, DePue JD, Monroe AD, et al. A population-based survey of physician smoking cessation counseling practices. Prev Med. 1998 Sep-Oct;27(5 Pt 1):720-729.

15. El-Guebaly N, Cathcart J, Currie S, Brown D, Gloster S. Smoking cessation approaches for persons with mental illness or addictive disorders. Psychiatr Serv. 2002 Sep;53(9):1166-1170.

16. Himelhoch S, Daumit G. To whom do psychiatrists offer smoking-cessation counseling? Am J Psychiatry. 2003 Dec;160 (12):2228-2230.
17. Price JH, Ambrosetti LM, Sidani JE, Price JA. Psychiatrists' smoking cessation activities with Ohio community mental health center patients. Community Ment Health J. 2007 Jun;43 (3):251-266.

18. Bartlem K, Bowman J, Ross K, et al. Mental health clinician attitudes to the provision of preventive care for chronic disease risk behaviours and association with care provision. $B M C$ Psychiatry. 2016 Mar 2;16:57. doi: 10.1186/s12888-016-0763-3.

19. Hall K, Kisely S, Urrego F. The use of pediatrician interventions to increase smoking cessation counseling among smoking caregivers: a systematic review. Clin Pediatr (Phila). 2016 Jun;55 (7):583-592. doi: 10.1177/0009922816632347.

20. Hall K, Kisely S, Gastanaduy M, Urrego F. Pediatricians' confidence and behaviors in smoking cessation promotion and knowledge of the Smoking Cessation Trust. Ochsner J. 2016 Summer;16(2):130-135.

21. Garg A, Serwint JR, Higman S, et al. Self-efficacy for smoking cessation counseling parents in primary care: an office-based intervention for pediatricians and family physicians. Clin Pediatr (Phila). 2007 Apr;46(3):252-257.

22. Frankowski BL, Weaver SO, Secker-Walker RH. Advising parents to stop smoking: pediatricians' and parents' attitudes. Pediatrics. 1993 Feb;91(2):296-300.

23. Pérez-Stable EJ, Juarez-Reyes $M$, Kaplan C, Fuentes-Afflick $E$, Gildengorin V, Millstein S. Counseling smoking parents of young children: comparison of pediatricians and family physicians. Arch Pediatr Adolesc Med. 2001 Jan;155(1):25-31.

24. Cluss PA, Moss D. Parent attitudes about pediatricians addressing parental smoking. Ambul Pediatr. 2002 Nov-Dec;2 (6):485-488.

25. Collins BN, Levin KP, Bryant-Stephens T. Pediatricians' practices and attitudes about environmental tobacco smoke and parental smoking. J Pediatr. 2007 May;150(5):547-552.

26. Cabana MD, Rand C, Slish K, Nan B, Davis MM, Clark N. Pediatrician self-efficacy for counseling parents of asthmatic children to quit smoking. Pediatrics. 2004 Jan;113(1 Pt 1):78-81.

This article meets the Accreditation Council for Graduate Medical Education and the American Board of Medical Specialties Maintenance of Certification competencies for Patient Care, Medical Knowledge, and Practice-Based Learning and Improvement. 